\title{
Combined vitreous and cataract surgeries in highly hyperopic eye
}

This article was published in the following Dove Press journal:

Clinical Ophthalmology

3 September 2010

Number of times this article has been viewed

\author{
Makoto Inoue ${ }^{1,2}$ \\ Kei Shinoda ${ }^{3}$ \\ Tomoko Matsuda- \\ Yamamitsu ${ }^{2}$ \\ Ronaldo Yuiti Sano' \\ Susumu Ishida 2,4 \\ 'Kyorin Eye Center, Kyorin University \\ School of Medicine, Mitaka, Tokyo, \\ Japan; '2Department of Ophthalmology, \\ Keio University School of Medicine, \\ Shinjuku, Tokyo, Japan; ${ }^{3}$ Department \\ of Ophthalmology, Teikyo University \\ School of Medicine, Itabashi, Tokyo, \\ Japan; ${ }^{4}$ Department of Ophthalmology, \\ Hokkaido University School of \\ Medicine, Sapporo, Hokkaido, Japan
}

Correspondence: Makoto Inoue Kyorin Eye Center, Kyorin University School of Medicine, 6-20-2 Shinkawa, Mitaka, Tokyo, I8I-86II, Japan Tel $+8 I-422-4755 I I$ ext 2606 Fax +8I-422-469309

Email inoue@eye-center.org

\begin{abstract}
We report a case of a patient with a highly hyperopic eye who underwent cataract surgery combined with vitreous surgery to create a posterior vitreous detachment (PVD) to prevent choroidal neovascularization (CNV). A 78-year-old man noticed a decrease in his vision due to a cataract in his right eye. The patient had a severe visual loss in his left eye because of a CNV 2 years after a cataract surgery. His visual acuities were 20/30 OD and 20/600 OS, and funduscopic examination showed an orange-colored lesion OD and degenerative subretinal fibrosis OS. The posterior vitreous was attached to the retina in both eyes. The axial length was $18.9 \mathrm{~mm}$ OD and $19.0 \mathrm{~mm}$ OS. Cataract surgery combined with vitreous surgery to create PVD was performed on the right eye, and the vision improved to 20/20 with no signs of developing $\mathrm{CNV}$ after 5 years. We conclude that cataract surgery combined with vitreous surgery to create a PVD may prevent the development of CNV in highly hyperopic eyes.
\end{abstract}

Keywords: hyperopia, macular degeneration, posterior vitreous detachment, cataract surgery

\section{Introduction}

Cataracts and age-related macular degeneration (AMD) are major ocular diseases of the elderly that can lead to severe vision decrease. A population-based study showed a high correlation between the presence of exudative AMD and history of cataract surgery and also between AMD and hyperopia. ${ }^{1,2}$ In addition, the posterior vitreous in most eyes that develop AMD is not detached. ${ }^{3}$ We report our successful treatment for cataract in a highly hyperopic eye without a posterior vitreous detachment (PVD). Of significance was the fact that the patient had undergone cataract surgery in his fellow eye that also did not have a PVD and had developed choroidal neovascularization (CNV) postoperatively.

\section{Case report}

A 78-year-old man noticed a decrease in vision in his right eye. The patient had a severe reduction of vision in his left eye due to a CNV that had developed 2 years after cataract surgery. Examination of his medical records showed that the vision in his left eye had gradually decreased from 20/25 to 20/600. On presentation, his vision was 20/30 OD and 20/600 OS, with refraction of +7.5 diopters (D) OD and +12.0 D OS. Slit-lamp examination showed a moderate cataract in the right eye and pseudophakia in the left eye. Funduscopic examination showed an orange-colored lesion but an absence of drusen around the macular area in the right eye (Figure 1A) and a degenerative subretinal scar in the left eye (Figure 2). A PVD was not present in both eyes, and optical coherence tomography (OCT Ophthalmoscope C7; Nidek Corp, Tokyo, Japan) showed 

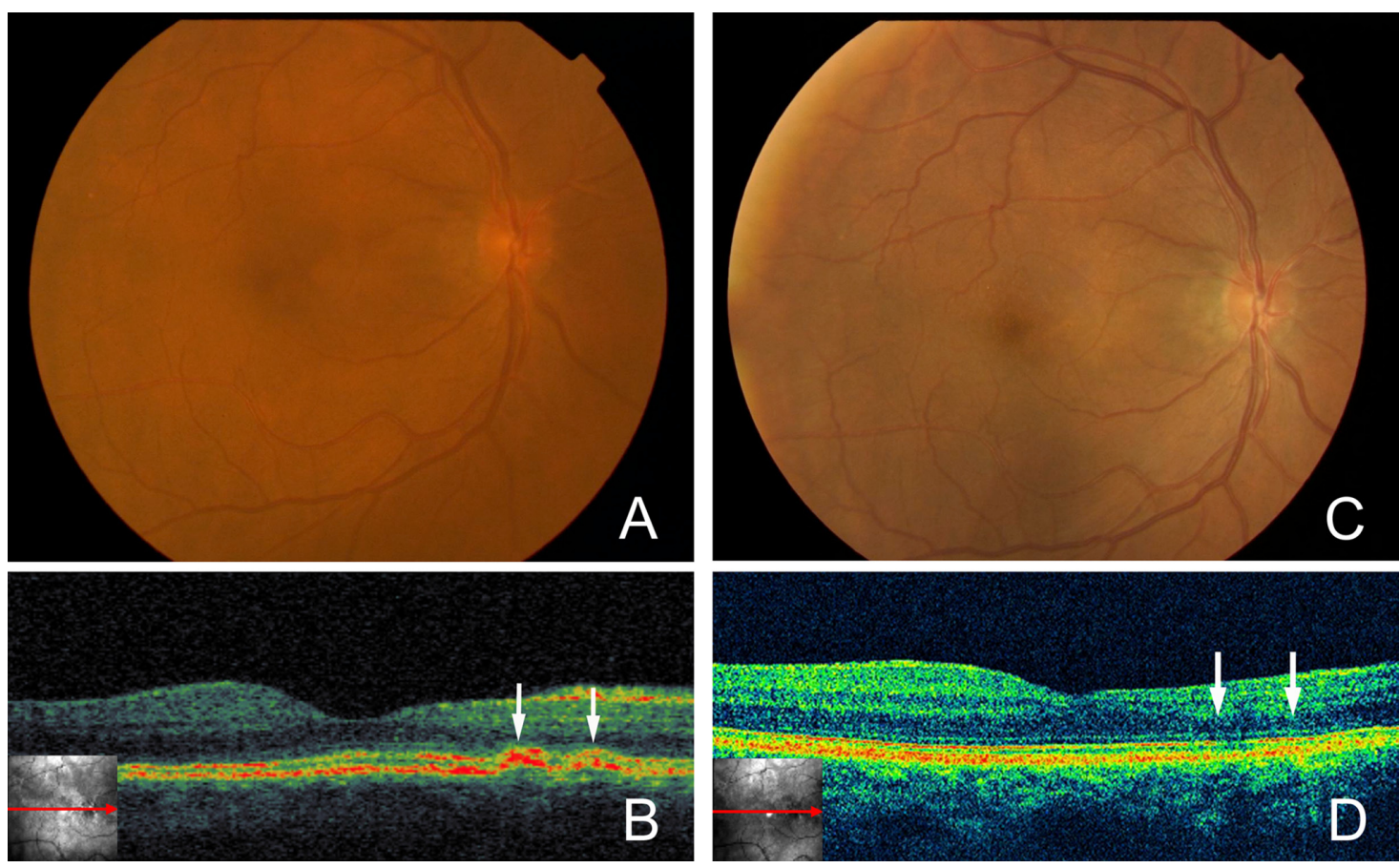

Figure I Preoperative and postoperative photographs and optical coherence tomographic (OCT) images of the right eye. A) An orange-colored lesion can be seen between the optic disc and the macula, but other findings are normal. B) Cross-sectional OCT image shows that the orange-colored lesion in the fundus photograph was a polypoidal choroidal vascular lesion (white arrows). C) Smaller size of orange-colored lesion can be seen years after the surgery. D) Cross-sectional OCT image showing regressed polypoidal choroidal vascular lesion (white arrows).

a polypoidal choroidal vascular lesion corresponding to the orange-colored lesions in the right eye (Figure 1B). The axial lengths were $18.9 \mathrm{~mm}$ OD and $19.0 \mathrm{~mm}$ OS.

Because of the poor outcome after cataract surgery in the left eye, vitreous surgery to create PVD was combined with the cataract surgery in the right eye after an informed consent was obtained. Triamcinolone acetonide was injected intravitreally to make the vitreous cortex more visible, and this showed that the posterior vitreous was firmly attached to

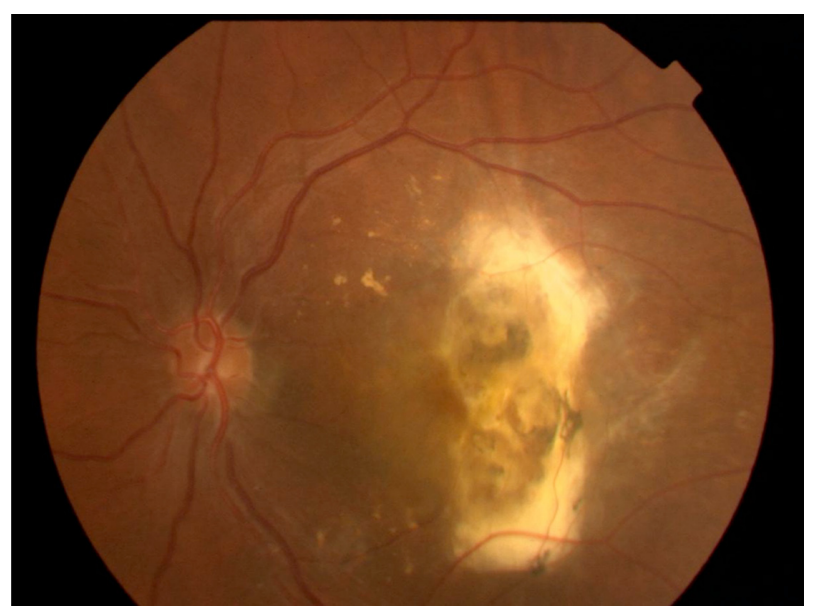

Figure 2 Preoperative fundus photograph of the left eye. Degenerative subretinal fibrosis can be seen. the macular area. A PVD was created, and the residual vitreous cortex above the macula was completely removed. An intraocular lens (VA60BB, +35.0 D; Hoya, Japan) was then implanted. The vision improved to $20 / 20$ with a refraction of +0.5 D. Funduscopic examination and OCT (OCT 4000 Cirrus HD-OCT; Carl Zeiss Meditec, Dublin, CA) performed 5 years later showed no sign of a developing AMD, and the OCT images showed reduction in polypoidal vascular lesion (Figures 1C and 1D).

\section{Discussion}

A population-based study reported that pseudophakic eyes had a 3-fold greater risk of developing AMD than phakic eyes, ${ }^{1}$ and another study reported that AMD was significantly associated with hyperopic refractive errors. ${ }^{4}$ It has also been reported that there is a higher incidence of a persistent central vitreoretinal adhesion in eyes with exudative AMD than in eyes with nonexudative AMD and age-matched control eyes. ${ }^{3}$ The authors concluded that the persistent attachment of the posterior vitreous cortex to the macula may be a risk factor for developing exudative AMD, and that vitrectomy to create a PVD may have prophylactic benefits. Relevant to our case, a regression of a CNV in eyes with AMD has been described after vitrectomy to create a PVD. ${ }^{5}$ We found a firmly adherent vitreous cortex around the macula, which 
may have caused the development of a CNV after the cataract surgery in the fellow eye.

A recent meta-analysis showed that neovascular AMD developed in the fellow eyes of eyes with untreated neovascular AMD in $12.2 \%$ of patients by 12 months and in $26.8 \%$ of patients by 4 years. ${ }^{6}$ However, the polypoidal choroidal vascular lesion in the affected eye of our case suggested that it was more likely polypoidal choroidal vasculopathy, which has a better natural course than neovascular AMD. ${ }^{7}$ It is difficult to draw a strong conclusion from a single case that removing vitreous traction reduces the risk of neovascular AMD; however, we recommend vitreous surgery combined with cataract surgery to create a PVD for preventing the development and progression of CNV in highly hyperopic eyes.

\section{Disclosure}

The authors do not have any financial support including any grants and funds in support of the study. The authors also do not have any financial and proprietary interest in any aspect of this report.

\section{References}

1. Cugati S, Mitchell P, Rochtchina E, Tan AG, Smith W, Wang JJ. Cataract surgery and the 10-year incidence of age-related maculopathy: the Blue Mountains Eye Study. Ophthalmology. 2006;113:2020-2025.

2. Wang JJ, Mitchell P, Smith W. Refractive error and age-related maculopathy: the Blue Mountains Eye Study. Invest Ophthalmol Vis Sci. 1998;39:2167-2171.

3. Krebs I, Brannath W, Glittenberg C, Tan AG, Smith W, Wang JJ. Posterior vitreomacular adhesion: a potential risk factor for exudative age-related macular degeneration? Am J Ophthalmol. 2007;144:741-746.

4. Xu L, Li Y, Zheng Y, Jonas JB. Associated factors for age related maculopathy in the adult population in China: the Beijing Eye Study. Br J Ophthalmol. 2006;90:1087-1090.

5. Ikeda T, Sawa H, Koizumi K, Yasuhara T, Yamasaki T. Pars plana vitrectomy for regression of choroidal neovascularization with age-related macular degeneration. Acta Ophthalmol Scand. 2000;78:460-464.

6. Wong TY, Chakravarthy U, Klein R, et al. The natural history and prognosis of neovascular age-related macular degeneration: a systematic review of the literature and meta-analysis. Ophthalmology. 2008; 115:116-126.

7. Uyama M, Wada M, Nagai Y, et al. Polypoidal choroidal vasculopathy: natural history. Am J Ophthalmol. 2002;133:639-648.
Clinical Ophthalmology

\section{Publish your work in this journal}

Clinical Ophthalmology is an international, peer-reviewed journal covering all subspecialties within ophthalmology. Key topics include: Optometry; Visual science; Pharmacology and drug therapy in eye diseases; Basic Sciences; Primary and Secondary eye care; Patient Safety and Quality of Care Improvements. This journal is indexed on

Submit your manuscript here: http://www.dovepress.com/clinical-ophthalmology-journal

\section{Dovepress}

PubMed Central and CAS, and is the official journal of The Society of Clinical Ophthalmology (SCO). The manuscript management system is completely online and includes a very quick and fair peer-review system, which is all easy to use. Visit http://www.dovepress.com/ testimonials.php to read real quotes from published authors. 